\title{
A instrumentalização do ser, mesmo antes de o ser: análise da obra literária Para a Minha Irmã, de Jodi Picoult
}

\section{The instrumentalization of the human being, even before becoming one: a review of the novel My Sister's Keeper, by Jodi Picoult}

\author{
Isabel Margarida de Figueiredo Silvestre \\ Universidade de Coimbra, Coimbra, Portugal. \\ msilvestre@netcabo.pt
}

Resumo: A bioética, enquanto ética prática aplicada ao estudo das ciências da vida, é um saber transdisciplinar, que une numa mesma reflexáo especialistas de várias áreas, incluindo a médica. E dentro da medicina, a procriação medicamente assistida surge como terreno fértil em questôes éticas, às quais os profissionais de saúde, juristas, governos e população em geral estáo cada vez mais atentos. A sensibilizaçáo global para estas questóes surge por diversas vias, sendo a literatura a mais tradicional, e os meios de comunicaçáo social, assim como o cinema, os mais populares. Este artigo pretende salientar a importância da literatura para a bioética, através da análise de uma obra literária específica: Para a Minha Irmá, de Jodi Picoult. Nesta obra de ficção é abordado o caso de uma criança nascida através do recurso ao diagnóstico genético pré-implantatório, para ser geneticamente compatível com uma irmã portadora de doença grave. No âmbito da narrativa, analisamse as questóes éticas, mas também médicas, familiares, sociais e até jurídicas que esta prática, autorizada pela lei vigente em Portugal, pode suscitar. Podemos concluir que a literatura é efectivamente um excelente meio de desenvolvimento da reflexão ética. Por outro lado, em áreas como a procriação medicamente assistida, o médico deve desenvolver competências éticas, sociais e humanas, que ultrapassam em muito os conhecimentos científicos e a capacidade técnica.

Palavras-chave: Diagnóstico genético pré-implantatório; procriação medicamente assistida; bioética; literatura.

Abstract: Bioethics, as the practical ethics applied to the study of life sciences, is a transdisciplinary knowledge. As a matter of fact, it is able to join in a single reflection experts from various fields, including the medical one. Within medicine, assisted reproductive technologies emerge as a fertile ground of ethical issues, of which health professionals, lawyers, politicians and general population are increasingly aware. The global perception of these questions arises in various ways, being literature the most traditional, whereas the media and the cinema are in fact the most popular. This paper aims to emphasize the importance of literature in bioethics, through the analysis of a specific literary work: $M y$ Sister's Keeper, by Jodi Picoult. This novel tells the story of a child born through the use of preimplantation genetic diagnosis, with the aim of being genetically matched with a sister carrier of a serious illness. Within the narrative, we analyze the ethical issues, but 
also medical, familiar, social and even legal issues that this practice, authorized by the Portuguese law, may raise. We can conclude then that literature is actually an excellent way of developing an ethical reflection. Moreover, in areas such as assisted reproduction, a medical doctor must have ethical, social and human skills that go far beyond scientific knowledge and technical competence.

Keywords: Preimplantation genetic diagnosis; assisted reproductive technologies; bioethics; literature.

A bioética, enquanto ética prática aplicada ao estudo das ciências da vida, no contexto dos novos conhecimentos biológicos e progressos biomédicos, é um saber transdisciplinar, que une, numa mesma reflexáo, especialistas de várias áreas. No entanto, é também uma ciência cada vez mais popular. À medida que os avanços técnico-científicos vão criando novos problemas, e estes vão sendo analisados no círculo restrito dos especialistas, vai emergindo uma consciencialização global relativamente aos mesmos.

$\mathrm{O}$ interesse pela bioética foi-se generalizando, por motivos e meios que passaremos a analisar. Desde logo, pela sua ligação com a vida. A vida passível de ser criada num laboratório, selecionada, manipulada, prolongada artificialmente... A vida ameaçada pela doença, fonte de atroz sofrimento, físico e psíquico, do próprio doente e dos que o rodeiam... A vida mantida pelo recurso a sucessivas terapêuticas, tantas vezes não curativas e geradoras de ainda mais dor ... Ainda a vida, cada vez mais exposta a agressóes químicas, físicas, radioativas, que ameaçam o equilíbrio dos ecossistemas e extinguem espécies... Todas estas realidades geram interesse não só no seio da comunidade científica, mas também na população em geral. E uma das grandes responsáveis por este facto é sem dúvida a literatura.

$\mathrm{Na}$ maioria das grandes obras literárias ficcionais dos últimos séculos, a presença da doença, do sofrimento e da morte é uma constante. E é difícil ficar indiferente a estes temas, e deixar de pensar nesta ficçáo como uma realidade que se pode instalar na vida de qualquer um, assim, sem aviso nem preparo, verdadeiro terramoto, desmoronando tudo à sua devastadora passagem.

Através da leitura podemos dar asas à nossa imaginação, vivenciar vidas e experiências vividas, deliberar, tomar decisóes. Entrar noutros mundos, e neles nos relacionarmos com os outros e connosco, como um outro. Desbravar novos campos, refletir, opinar, concluir.

Morris, ao escrever sobre narrativa, ética e dor, introduz a expressão "pensar com histórias". Na sua reflexão sobre a importância das histórias na nossa vida cita McIntyre, que ao escrever sobre teoria moral, descreve o Homem como um animal essencialmente contador de histórias. Morris refere ainda que a narrativa não nos diz necessariamente o que está certo ou errado. $\mathrm{O}$ que a narrativa oferece à bioética são meios para aumentar a compreensão dos múltiplos valores e perspetivas em conflito na ação ou inação médica (1). Para Ricouer, a narrativa nunca é eticamente neutra, e é o primeiro laboratório do julgamento moral (2). Hunter entende a narrativa como fulcral para a bioética, pois 
não só dá oportunidade de reflexão moral imaginativa, como constitui terreno para argumentação moral (3). Magalhães também considera que a ficção nos permite praticar a tomada de decisóes éticas, ao focar aspetos particulares da narrativa, e experimentando aplicar-lhes as teorias e princípios éticos (4).

\section{A escolha da obra}

Todas as obras literárias podem ser alvo de uma análise bioética, e muitas também um excelente instrumento de sensibilização para estas questóes. Quantas vezes não lemos livros, cuja intensidade nos toca de tal forma, que passam a viver na nossa memória, nos nossos atos, na nossa vida... Foram estes os sentimentos despertados pelo livro Para a Minha Irmã (5). Uma catadupa de emoçóes: ao vestir o papel de médica, que sou, perante os pais de uma criança doente, tendo que os informar e esclarecer com rigor e verdade, mas também ajudando a lidar com esta incomensurável dor; e ao vestir o papel de mãe, que também sou, procurando lutar, de um modo bem menos racional, pela vida, saúde e bem-estar de uma filha táo doente. Mas ainda no papel de máe, que consumida nesta luta hercúlea contra a doença de uma filha, fica esgotada, sem espaço e sem tempo para os outros filhos, tão carentes de mãe.

Senti também um impulso enorme em proteger a pequena Anna, instrumento criado para salvar a irmã doente, repetidamente utilizado para a tratar, que num gesto de aparente autodeterminação diz "BASTA!"... mas apenas quer ajudar a irmá, que decidiu parar de lutar contra a doença que a consome. Quis também proteger Kate, a filha doente, perseguida pelo espetro de uma doença gravíssima, que quando parece debelada irrompe das profundezas do seu ser, tentando aniquilá-la numa luta titânica, que esta mãe não desiste de vencer. E finalmente, senti uma enorme vontade de acolher o filho Jesse que, perdido e só no seio desta família indisponível, envereda por comportamentos desviantes e de risco, como forma de chamar a atenção, mas esbarra com uns pais que desistiram dele, mesmo antes de o tentarem ajudar.

Para além destas reaçóes, mais imediatas e superficiais, este livro fez-me mergulhar numa profunda reflexão sobre a criação e destino dos embriôes excedentários, a instrumentalização do ser humano, a vulnerabilidade e autonomia do doente e da criança, a responsabilidade dos pais pelo bem-estar dos seus filhos, a beneficência e náo maleficência, e também a justiça. É esta reflexão que vou passar a partilhar.

\section{Análise da obra literária Para a minha irmá}

A obra literária Para a Minha Irmá aborda a vida da família Fitzgerald, aparentemente normal e feliz, até ao momento em que é diagnosticada uma forma rara e grave de leucemia à filha mais nova, Kate, então com dois anos. Perante a necessidade de um transplante de medula, não existia nenhum dador compatível, nem mesmo o irmão mais velho, Jesse. Então os pais, Sara e Brian, recorrem a uma técnica de reprodução assistida - o diagnóstico genético pré-implantatório (DGPI) - para conceber um filho geneticamente compatível com a filha doente. E assim nasce Anna. Com o sangue do 
cordão umbilical de Anna, Kate é tratada e entra em remissão. Mas as recidivas sucedemse, e sempre que Kate é internada para novo tratamento, Anna é internada com ela, e submetida aos necessários procedimentos, muitas vezes dolorosos e invasivos, para doar à irmã aquilo que esta vai precisando: linfócitos, plaquetas, medula óssea... Quando Kate entra em insuficiência renal, é necessário um transplante de rim. E, mais uma vez, Anna é considerada uma dadora naturalmente disponível. E é neste ponto que, surpreendendo tudo e todos, Anna decide náo querer doar um rim à irmá, e contrata um advogado para pedir a sua emancipação médica. Esta decisão cria forte tensão na relação entre Anna e a mãe, que sendo advogada, embora sem exercer desde o nascimento dos filhos, assume a sua própria defesa contra a filha. Este processo termina em tribunal, com o juiz decidindo a favor da emancipação de Anna. Enquanto isto, Kate encontra-se internada num estado de tal modo crítico, que os médicos receiam que não sobreviva à cirurgia de transplante. O livro termina de uma forma inesperada, com a morte de Anna num acidente de viação, à saída do tribunal. E é já cadáver que Anna acaba por doar o rim a Kate.

Anna cumpre entáo o propósito com que nasceu, salvar Kate.

\section{Título}

O livro Para a Minha Irmã tem, na versão original inglesa, o título My Sister's Keeper, ou seja, a guardiã da minha irmã. Este título original centraliza a ação no papel protetor de Anna em relaçáo a Kate. Anna nunca se opôs a qualquer tipo de ajuda ou apoio que lhe fosse solicitada pela e para a irmá, e é frequentemente a primeira a ajudar e cuidar de Kate nas várias crises que se váo sucedendo. A sua recusa em continuar a ser dadora da irmá, mal entendida como um ato de não solidariedade e não beneficência, é a forma que Anna encontra para proteger Kate, a qual, querendo exercer a sua autonomia, pretende parar os tratamentos e morrer em paz.

No entanto, também podemos interpretar este título em sentido inverso, ou seja, como sendo Kate, tocada pela dedicação e amor incondicional da sua irmá mais nova, sua grande amiga, sempre ao seu lado nos bons e maus momentos, que decide protegê-la de tantas agressóes, e resolve desistir de viver, para libertar a Anna e a deixar ter uma vida normal.

$\mathrm{Na}$ tradução portuguesa, mesmo considerando o ser dadora e não guardiá, a dualidade anteriormente referida persiste: tanto podemos considerar que é Anna a dadora constante de carinho, afecto, cuidados e também das partes do seu corpo que forem sendo necessárias, como Kate, que num ato do mais puro altruísmo, prefere prescindir de viver para dar a Anna a liberdade que esta não consegue ter.

\section{Autora}

A autora desta obra, Jodi Picoult, nasceu a 19 de Maio de 1966, em Long Island, nos Estados Unidos da América. Estudou inglês e escrita criativa na Universidade de Princeton, e fez um mestrado em educação pela Universidade de Harvard. Casou-se com Tim Van Leer, que conheceu na universidade. Estava grávida do primeiro filho quando 
escreveu o seu primeiro romance, Cançóes da Baleia Jubarte, o qual foi publicado em 1992. É autora de dezanove romances, todos best sellers, e em 2003 foi galardoada com o New England Bookseller Award for Fiction (6,7).

Jodi e Tim têm três filhos. O filho do meio, Jake, teve um colesteatoma, tumor do ouvido, que embora benigno, pelo seu crescimento poderia levar à morte. Jake foi submetido a 10 cirurgias em três anos, tendo ficado parcialmente surdo (7). Esta vivência parece influenciar o modo de escrever de Jodi Picoult, sobre problemas do foro médico e questóes éticas delicadas, que gosta de abordar sob diversas perspetivas. Sendo as suas histórias tão tocantes e plenas de dramas familiares e humanos, não é de estranhar que várias tenham já sido adaptadas ao cinema: é o caso de Para a Minha Irmã, que estreou em 2009.

\section{Personagens}

A acção deste livro vai-se desenrolando através das várias personagens, que se vão expressando alternadamente na primeira pessoa, expondo os seus sentimentos, a sua vivência dos problemas, as suas opiniốes. Tudo gira em torno não de Kate, mas da sua doença e da luta contra a sua morte.

Anna é a primeira personagem a ser introduzida, e que se assume, logo na primeira página, como um meio para atingir um fim: “... eu nasci com um fim específico" (5). É este sentimento que prevalece em toda a narrativa, apesar da mãe a querer fazer acreditar no contrário: "A minha mãe fez questão de me dizer que ainda gostava mais de mim porque sabia exatamente o que ia esperar" (5).

Kate é a personificaçáo da doença, permanece invisível durante toda a narrativa, e só fala no final, quando a irmá morre. Com um confesso sentimento de culpa, afirma: "É que alguém tinha que ir, e a Anna foi no meu lugar" (5). E com uma enorme saudade e sensação de perda, termina dizendo: "Penso no seu rim a trabalhar dentro de mim, e no seu sangue a correr nas minhas veias. Eu levo-a comigo, para onde quer que vá" (5).

Para Sara, a obsessão de salvar a filha tornou-se o motor e único objetivo da sua existência. Perante a doença de Kate e a possibilidade da sua morte, decide:”... temos que nos assegurar de que isso não aconteça" (5).

Brian apresenta-se dizendo: "Se eu não fosse bombeiro, seria astrónomo" (5). Escolhe o nome de uma constelaçáo, Andrómeda, para verdadeiro nome de Anna. Na mitologia grega, Andrómeda era filha dos reis da Etiópia, e foi acorrentada a um rochedo para ser devorada por um monstro, sacrifício exigido a seu pai para salvar o reino; na respetiva constelação, Andrómeda é representada com os braços esticados e mãos acorrentadas. Esta imagem é muito sugestiva da vida de Anna, sempre acorrentada à sua irmã Kate. Brian encontra no quartel e na sua nobre profissão os seus refúgios, mas consegue enfrentar Sara, acompanhando e apoiando Anna enquanto aguardam a audiência.

Jesse está completamente deslocado na família. Deixou de haver espaço para ele desde que Kate adoeceu. É inseguro e carente, tem uma péssima auto-estima "Tenho a certeza que valho muito mais morto do que vivo" - e ateia o fogo, procurando chamar a atenção do seu pai bombeiro. Isto além de beber, fumar droga, roubar e outros 
comportamentos desviantes que, segundo Anna, "ele não queria que os pais vissem... nem os pais queriam realmente ver" (5).

Neste livro há outras duas personagens a considerar: Campbell, advogado de Anna, e a sua ex-namorada Julia, curadora ad litem de Anna neste caso judicial. Estas personagens vão-se entrecruzando com as anteriores, o seu caso amoroso mal resolvido vai finalmente encontrar uma soluçáo, e vão distraindo o leitor da intensidade dos problemas da família Fitzgerald.

\section{Questóes éticas}

Um ponto importante abordado nesta obra é a questão do recurso ao DGPI, que consiste na seleção de embrióes com as características pretendidas, criados por uma técnica de reprodução assistida, para transferir para o útero materno. O DGPI destinase essencialmente a evitar o nascimento de crianças com doenças genéticas consideradas graves, excluindo os embrióes com a alteração que se pretende evitar. No entanto, também pode ser utilizado para salvar um familiar portador de doença grave e potencialmente fatal, selecionando para o efeito embrióes geneticamente compatíveis (8). Esta última indicação terapêutica do DGPI, que encontramos em Para a Minha Irmã, levanta mais problemas éticos do que a anteriormente referida, não só porque os embrióes excluídos sáo embrióes normais, e portanto merecedores de respeito pelo potencial de vida que representam, mas também pela potencial instrumentalização exercida sobre a criança a nascer, considerando-a um meio de salvação de outro ser humano e não um fim em si. É também importante ter em consideraçáo que o DGPI é um procedimento que, além de invasivo, é dispendioso e tem um sucesso reduzido: não só a taxa de gravidez é, em média, de apenas $25 \%$, como poderemos nem sequer obter embrióes com as características desejadas para transferir.

Jodi Picoult não aborda o problema ético dos embrióes saudáveis que são descartados. Bastaria uma questão a este respeito, por parte de Sara ou Brian, ao médico que lhes apresentou esta possibilidade, para podermos ter este importante tema de reflexão bioética a enriquecer esta obra.

Por outro lado, o problema da instrumentalização de Anna é notório e constante ao longo de todo o romance, chegando a ser desconcertante a naturalidade com que ela é utilizada sempre que necessário, e impedida de se afastar para se encontrar sempre disponível. E é assim que a própria Anna se sente, um verdadeiro utensílio, com um destino programado desde a sua concepçáo. Chega a ter pesadelos, em que imagina: "sou cortada em tantos pedaços que não resta nada de mim para ser reconstituido" (5).

Ainda no âmbito desta indicação para DGPI, uma outra reflexão poderá ter lugar: será que os médicos, ao sugerirem o DGPI a uns pais, desesperados e na eminência de perder um filho, não poderão estar a exercer uma certa forma de coerção, impelindoos para esta solução quando mais nada parece resultar? E se os pais não aceitarem esta possibilidade, não lhes poderão causar um terrível sentimento de culpa por não terem feito tudo o que podiam para salvar o filho?

Outras questóes que poderemos analisar nesta obra são a da autonomia, quer 
dos pais quer de ambas as filhas, e também a da responsabilidade dos pais, pelas decisóes autónomas que tomam em relação às filhas. Quando os pais consideram ter um filho para tratar outro, tornam-se responsáveis por todas as decisóes de caráter médico relativas a ambos. Contudo, isto não os deve impedir de agir de acordo com a vontade dos filhos, pondo-os a par dos acontecimentos e atuando de acordo com os seus desejos. Este respeito pela autonomia das filhas está completamente ausente em Para a Minha Irmã. Anna sempre foi usada sem ser informada, nunca houve qualquer cuidado em tentar apreender o que esta criança, totalmente vulnerável na mão dos pais, gostaria de fazer relativamente à irmá. E mesmo quando ela ousa proclamar a sua autonomia e recusar-se a doar o rim a Kate, esta decisão não é aceite pela mãe, que luta em tribunal pela possibilidade de fazer operar Anna contra a sua própria vontade. Em relaçáo a Kate, a sua autonomia também não é apreendida e posteriormente respeitada; não é consultada sempre que novas decisóes são tomadas relativamente à sua pessoa, e assiste, também completamente vulnerável, ao exercício do poder dos pais. A obsessão da mãe em a curar é de tal forma sufocante que Kate, esgotada e cansada de tanto sofrer, ao pretender parar com os tratamentos, só encontra uma forma - recorrer à sua irmá, amiga e confidente, Anna.

Para a European Society of Human Reproduction and Embriology Task Force on Ethics and Law (ESHRE-TFEL), só quando a criança é fruto de uma escolha intencional e não do acaso, é que emerge a ideia do respeito pela criança como futuro ser autónomo e com os seus próprios interesses (9). Se legalmente a criança só é autónoma a partir de uma idade definida, eticamente não deve ser tomada qualquer decisão médica relativamente a um menor sem o informar e esclarecer, de acordo com a sua maturidade (10).

A ESHRE-TFEL considera também que os pais respeitam a autonomia da criança dadora, desde que a doação não seja o único motivo para esta ser concebida; devem querer amá-la e cuidá-la da mesma forma que amam e cuidam do filho doente. Se isto acontecer, a futura criança não é criada apenas como um instrumento, para benefício do irmáo doente (11). Não é o que se passa no seio desta família, onde tudo gira à volta da filha doente, estando os outros dois filhos sistematicamente em segundo plano, uma até ser preciso doar algo mais, o outro completamente abandonado e entregue a si próprio.

Segundo Patrão Neves, o poder de autonomia encontra o justo equilíbrio legitimador da sua moralidade, quando contrabalançado pelo dever da responsabilidade (12). Sara e Brian não só ignoram a autonomia dos filhos, como exercem a sua própria autonomia sem o indissociável dever de responsabilidade, como se pode verificar através da obstinação terapêutica demonstrada em relação a Kate, da não aceitação da emancipação médica de Anna, e ainda pela total demissão do seu papel de pais em relação a Jesse.

Existe na sociedade a presunção de que os pais agem para o benefício dos filhos, e com base nisto têm o direito de tomar decisóes sobre o que lhes deve ser feito. Todavia, em alguns casos, os interesses dos filhos podem entrar em conflito, e surge o dilema de ter que ponderar os interesses de ambos (11). Nesta obra, os interesses de Anna nunca foram tidos em conta, até ela se recusar a doar o rim à irmá. A sua vida escolar era interrompida sempre que Kate era internada, a sua vida social condicionada pela irmá doente, chegando a ser impedida de ir acampar longe de casa, não se desse o caso de ser necessária e não estar disponível. 
Os interesses de Jesse ficaram tão frequentemente para segundo plano, náo havendo tempo para o levar ao dentista ou para lhe comprar o que precisava, que este desistiu de reclamar tempo para si e para as suas necessidades. Contudo, o apelo por atençáo nunca parou: "Estava apenas a tentar chegar a um lugar em que reparassem em mim" (5), assume Jesse quando o pai o vai buscar à esquadra, detido por descer a rua de skate no meio do trânsito.

Ainda no campo do melhor interesse das crianças, se o nascimento de Anna para salvar Kate constitui um claro benefício para a criança doente, Anna só poderia daí obter vantagens psicológicas, como a melhoria da sua auto-estima, o que não é visível ao longo da narrativa. Por outro lado, enquanto a doação de Anna a Kate se resumiu às células estaminais do sangue do cordão umbilical, colhidas no momento do seu nascimento, não adveio daí qualquer prejuízo para Anna, pois não só o produto colhido seria desperdiçado, como também o ato da colheita é inócuo, não invasivo e não gerador de sofrimento para a criança recém-nascida. Contudo, o mesmo não se pode dizer de outros procedimentos a que foi sujeita posteriormente, como administração de fatores de crescimento, sucessivas colheitas de sangue e medula, por vezes com necessidade de anestesia geral. Aqui sim, houve desrespeito pelo princípio da não maleficência em relação a Anna, pois os referidos atos são invasivos, dolorosos e têm potenciais efeitos secundários não negligenciáveis. Isto para não falar da hipótese de doação de um rim em vida, o que comportaria riscos ainda mais consideráveis para a dadora. No entanto, e ao longo de todo este processo, o prejuízo para Anna é não apenas físico, mas também psicológico e social, decorrente dos sucessivos internamentos a que é sujeita, a par com a irmá, assim como de toda uma vida condicionada e limitada pela doença de Kate.

Quanto a Kate, é de ponderar se tanto investimento não ultrapassa os limites da beneficência e entra na esfera do encarniçamento terapêutico, colocando acima da qualidade de vida o prolongamento da mesma, a qualquer custo.

A narrativa levanta também outra questão pertinente, a da solicitude, ou seja, a predisposiçáo para estar presente, em resposta à fragilidade do outro. Kate é o objecto de solicitude de toda a família, pela sua vulnerabilidade. É fonte de preocupaçáo constante de todos os que a rodeiam, como elemento mais frágil deste núcleo familiar. Todavia, existem também outros vulneráveis, esquecidos, que em diversos momentos apelam também à solicitude e apoio dos pais: é o caso de Anna, particularmente enquanto aguarda o julgamento contra os pais; é também o caso de Jesse, perdido e sem rumo, desesperadamente à espera que dêem pela sua presença.

Uma última palavra relativamente à justiça, não na vertente da equidade distributiva dos recursos médicos, mas na da obstinação terapêutica. Não é justo prosseguir investindo sem saber parar, quer para com Kate, que assiste impotente à tentativa de prolongar a sua vida a qualquer preço, quer para com os outros, sendo estes outros a família que se afunda, desestruturada, sugada por este cancro que a consome há anos. 


\section{Conclusóes}

Para a Minha Irmã é uma obra absorvente, intensa, que me fez refletir sobre várias realidades e de diferentes perspetivas. Fez-me vivenciar a complexidade ética do DGPI para seleção de um bebé-medicamento (ou, se quisermos dar uma conotação mais positiva, de um bebé-salvador), muito para além dos aspetos relacionados com a técnica e a criação de embrióes, que apesar de normais são descartados. Alertou-me para a necessidade de proporcionar apoio psicológico a toda a família, não apenas na fase inicial de avaliação e decisão pela técnica, mas de uma forma contínua e ao longo do tempo. Mostrou-me como os médicos têm que estar preparados para acompanhar estas famílias, através de competências que não só a científica, e serem verdadeiros portos de abrigo destes barcos à beira do naufrágio. E ainda como têm que ajudar a saber parar e querer deixar de investir, sempre que o prolongamento da vida comprometa a dignidade e a qualidade da mesma para além do razoável.

Analisando a situaçáo pelo lado da família, discordo da atitude adotada em relaçáo à pequena Anna, que nunca foi consultada ou ouvida, de forma a procurarem ter noção daquilo que ela pensava, sentia, queria e estaria disposta a dar, sem coação. Mesmo quando ela ousou falar e se recusou a doar um rim, a sua vontade não foi aceite! Quanto a Kate, a partir do momento em que teve discernimento para apreender aquilo que lhe era proposto fazer, também ela deveria ter tomado parte ativa nas decisóes relativas à sua pessoa.

Uma última palavra relativamente aos pais, que na perspetiva de poderem perder uma filha, escolheram ter outro filho para a tratar. E centralizaram toda a sua existência na tentativa de salvar Kate. Falharam em relação aos filhos não doentes, para os quais nem sempre sobrou toda a disponibilidade desejada, mas para quem nunca deveria ter faltado amor, um amor sentido, afirmado, expresso pelos mais diversos meios possíveis.

E termino como comecei, referindo que a obra e a bibliografia que consultei para a elaboração deste trabalho me marcaram, não só pelo tema e pela forma como foi abordado, mas também pela consciencialização, que não tinha previamente, da enorme importância da narrativa para a reflexáo bioética. Mas acrescento ainda que a maternidade é para mim uma vivência de tal forma extraordinária, intensa, exclusiva, que diariamente a tento proporcionar a quem a deseja e não a alcança. E por isso assumo, enquanto mãe que sou e como o sou, que também eu recorreria ao DGPI para tentar salvar um filho.

\section{Referências}

1. Morris, D B. Narrative, Ethics, and Pain: Thinking with Stories. Narrative. 2001; 9 (1):55-77.

2. Ricouer P. Soi-même comme un autre. Paris: Éditions du Seuil; 1990.

3. Hunter KM. Narrative. In: Post SG, editor. Encyclopedia of Bioethics. 3a ed. Cleveland: Macmillan; 2004. p. 1875-1879.

4. Magalhães S, Araújo J, Carvalho AS [internet]. Bioethics education on deliberation: 
a view of a novel: Blue Gold, by Clive Cussler. In: Conference Bioethics Education: contents, methods, trends - Program and Book of Abstracts; 2010, Zefat, Israel, p.20 [acedido em em 18/set/2011]. Disponível em: http://hdl.handle.net/10400.14/2866.

5. Picoult J. Para a minha irmã. Porto: Civilização Editora; 2004.

6. Miller EC [internet]. Jodi Picoult Biography [acedido em 16/out/2012]. Disponível em: http://bestsellers.about.com/od/authorprofilesaz/p/jodi_picoult.htm.

7. Cunha B [internet]. Jodi Picoult. [acedido em 18/set/2011]. Disponível em: http:// oprazerdaleitura.webnode.com.pt/news/biografia-jodi-picoult.

8. Portugal. Presidência do Conselho de Ministros. Conselho Nacional de Ética para as Ciências da Vida [internet]. Parecer n. ${ }^{\circ}$ 51/CNECV/07 de 10 de abril de 2007. Parecer sobre diagnóstico genético pré-implantação. Disponível em: http://www.cnecv.pt/admin /files/data/docs/1273054175_P051_ParecerDGPI.pdf

9. Pennings G, et al. Taskforce on Ethics and Law 13: The welfare of the child in medically assisted reproduction. Hum Reprod. 2007;22(10):2585-2588.

10. Portugal. Ordem dos Médicos. Plenário os Conselhos Regionais [internet]. Código Deontológico da Ordem dos Médicos de 26 de setembro de 2008 - [acedido em 20 de Setembro de 2011]. Disponível em: https://www.ordemdosmedicos.pt/ index80e95574250dabe07151bdc23\&id=cc42acc8ce334185e0193753adb6cb77

11. Shenfield F, Pennings G, Cohen J, Devroey P, Tarlatzis B. Taskforce 9: the application of preimplantation genetic diagnosis for human leukocyte antigen typing of embryos. Hum. Reprod. [internet]. 2005 Abr.;20(4):845-7. Disponível em: http://www.ncbi.nlm. nih.gov/pubmed/15705626

12. Patrão-Neves MC. A problemática contemporânea da autonomia moral. In: Brito JHS, coord. Temas fundamentais de ética. Braga: Publicaçóes da Faculdade de Filosofia UCP; 2001. p.143-178.

Recebido: 19/07/2012 Aprovado: 29/10/2012 